\title{
EDITORIAL
}

\section{Como fazer poesia visual}

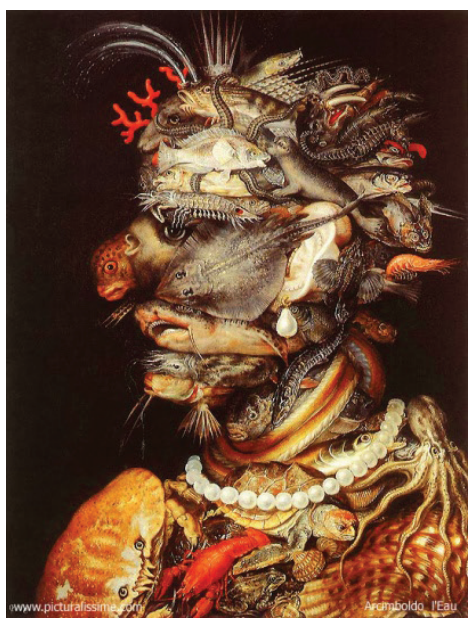

Giuseppe Arcimboldo. Série dos quatro elementos. Água. 1566. Kunsthistorisches Museum, Vienna, Áustria.

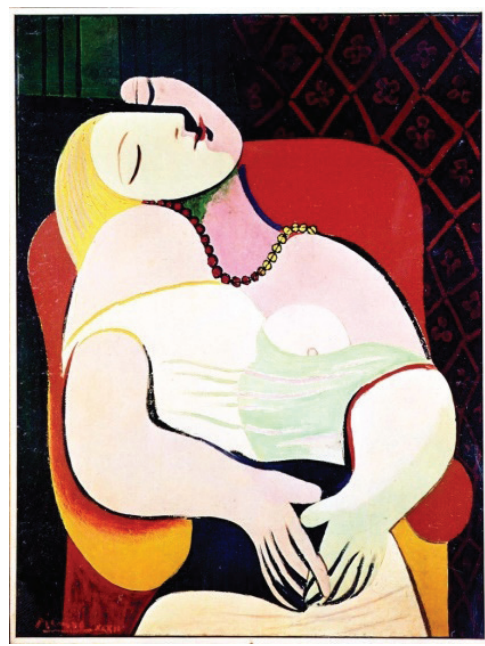

Pablo Picasso. O sonho. 1932. Coleção particular.
A edição de número 17 de RuMoRes, revista científica online dedicada aos estudos de comunicação, linguagem e mídias, traz em seu Dossiê uma homenagem ao trabalho do pesquisador Eduardo Peñuela Cañizal, importante influência nos estudos das poéticas da imagem em seus formatos pictórico, fotográfico e audiovisual. Peñuela foi professor da Escola de Comunicações e Artes da USP (ECA-USP) e de outras instituições de ensino, como a Universidade Tuiuti do Paraná (UTP) e a Universidade Paulista (Unip). Deu uma importante contribuição não só para a área específica de estudos que mencionamos, mas para a fundação e consolidação da pesquisa em comunicação no país.

O Dossiê Poéticas da Imagem pretende, assim, resgatar o legado de seu pensamento teórico, bem como fazer um percurso pelo testemunho de colegas pesquisadores que com ele conviveram em diversas etapas de sua carreira. Nesses dois âmbitos, podemos dizer que sua presença foi marcante. Sua visada para as imagens advinha da busca por rupturas e instabilidades nelas instaladas, apoiando-se especialmente em teorias das artes, da linguagem, do cinema e da psicanálise. Como colega e professor, influenciou trabalhos e abriu perspectivas, das quais podemos acompanhar derivações plurais aqui apresentadas. 


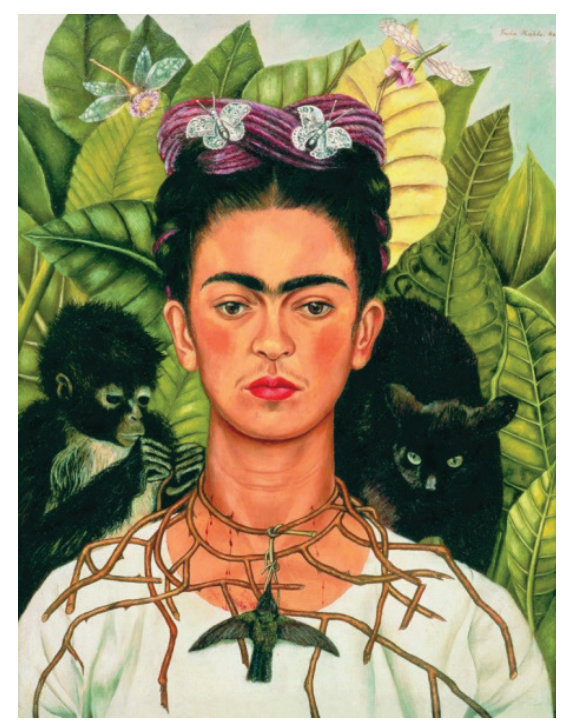

Frida Khalo. Autorretrato com colar de espinhos e beija-flor. 1940. Harry Ransom Center, Austin, Texas, EUA.

Por se inscreverem entre a memória, lembrança e o afeto, os artigos possuem singularidades e derivas. O texto de apresentação do Dossiê, intitulado Da amizade, foi escrito em 2014 por Sandra Fischer e originalmente pensado como uma homenagem. A autora, que também assina um dos artigos, gentilmente aceitou 0 convite para publicar o texto como parte desta edição, ao mesmo tempo registrando e evocando a trajetória de Eduardo Peñuela. Por seu caráter testemunhal, sua abertura se coloca em pelo menos dois sentidos: como possível chave de compreensão dos demais artigos e como um modo de reconhecimento do amigo e mestre.

Em Do espanto ao questionamento, Etienne Samain recompõe uma história das artes visuais a partir da análise de dois ensaios, um escrito por Georges Didi-Huberman e o outro por Eduardo Peñuela Cañizal. Mayra Rodrigues Gomes articula, em Memórias inscritas nas imagens, seu convívio pessoal e intelectual com o homenageado através do resgate da memória de histórias atravessadas pelas imagens e, essas imagens, pelo cruzamento do desejo.

Trazendo os conceitos para

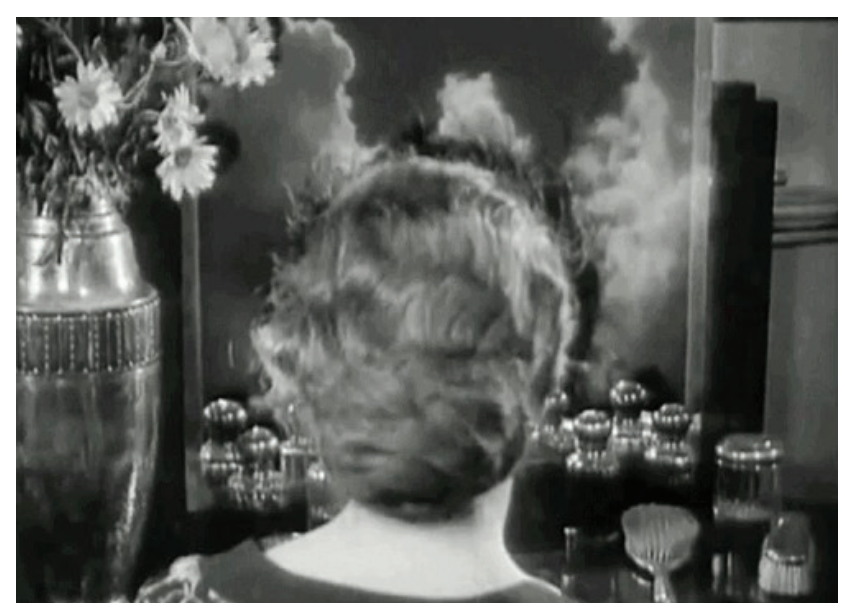

A idade do ouro. Direção: Luís Buñuel.

França, 1930, 60 minutos.

a tela da televisão, Anna Maria Balogh estuda vinhetas televisivas em Poética da imagem e TV: vinhetas de abertura e encerramento em programas ficcionais brasileiros. O artigo A corrosão do relato falocêntrico em "A favorita" e "Avenida 
Brasil": vestígios de um certo Almodóvar?, de Sandra Fischer, recupera o conceito anteriormente observado por Eduardo Peñuela em relação à obra do cineasta espanhol. Seguindo ainda na observação de imagens fora do âmbito cinematográfico, Rafael Venancio aponta a poética da imagem na obra do artista Géo Ham, perseguindo seu movimento-cristal.

Eduardo Peñuela incluía, também nessa perspectiva poética, a possibilidade do desconforto e do estranho. É o que recupera Laura Canepa em Senhor Babadook, Vincent e o horror materno: intertextos, analisando as relações intertertextuais entre os filmes de Jennifer Kent e de

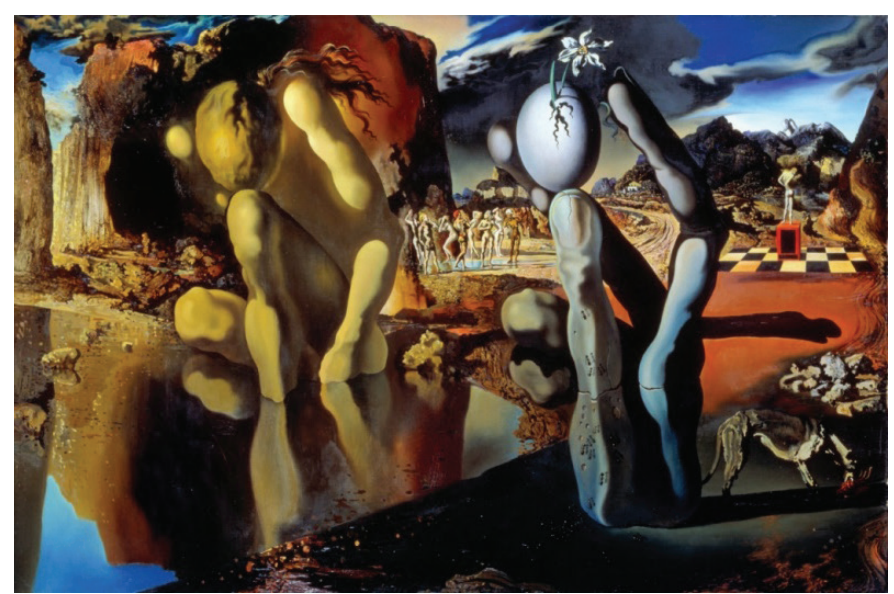

Salvador Dalí. A metamorfose de Narciso. 1937. Tate Modern, Londres, Reino Unido.

Tim Burton. Encerrando

o Dossiê, Dulcília Buitoni

propõe outro percurso seguindo o trajeto de Eduardo Peñuela em Eduardo Peñuela, mestre de intensas poéticas.

Os demais artigos de RuMoRes, agrupados em temas livres, seguem tratando das questões imagéticas, apontando, para além do Dossiê, abordagens teóricas também correlacionadas à obra de Peñuela. Nessa trilha, Mauricio Bragança tematiza as narrativas associadas ao tráfico de drogas em Imagens de ostentação nas narconarrativas: consumo e cultura popular, investigando a produção de imagens e seus modos de apropriação. Já Luiz Antonio Mousinho Magalhães volta seu olhar para a série televisiva "Capitu", dirigida por Luiz Fernando Carvalho, no artigo O bruxo solto: recepção crítica da microssérie Capitu, analisando a recepção crítica da obra e a abertura dialógica em sua estrutura.

Elegendo o cinema da retomada como tema, Gabriela Marinho, João Nery e Werick Andrella buscam as marcas da presença de classe em A classe média 
vai ao paraíso: representações no cinema da retomada. Do estabelecimento de identidades sociais passamos, com Miriam Viviana Gárate em Os "latinos" viajam à Meca do cinema, a observar relatos que envolvem a viagem a Hollywood paralelamente à expansão da indústria cinematográfica nos Estados Unidos. A edição se completa com a resenha de André Moraes à obra de Thomas A. Bredehoft: The visible text: textual production and reproduction from Beowulf to Maus (O texto visível: produção e reprodução de textos de Beowulf a Maus), imaginando o futuro do livro a partir de seu passado.

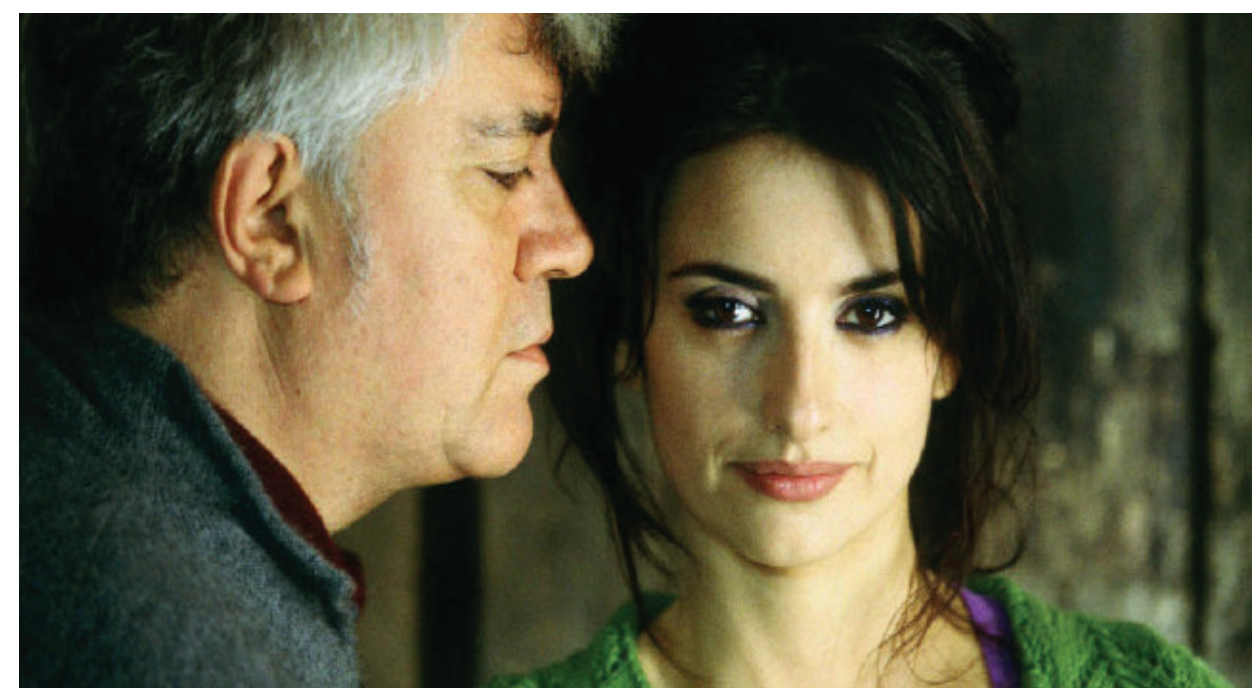

Volver. Direção: Pedro Almodóvar. Espanha, 2006, 120 minutos.

As imagens que acompanham este editorial são algumas das telas analisadas por Eduardo Peñuela em suas aulas e seus textos. A poética das imagens, em suas variadas configurações e desvios, estimula a pensar tanto o movimento nas imagens consideradas estáticas, como a captura do olhar por um frame dentro de uma sequencia de imagens. Atravessado de um a outro caso, o trabalho de Eduardo Peñuela nos aponta recortes, condensações, deslocamentos nas tomadas inesperadas de sujeitos em horizontes de telas partidas. A poética dá vida não à certeza de ver, mas à instabilidade de olhar. Poéticas que esperamos fazerem-se presentes nos artigos de RuMoRes e em seus deslocamentos, condensando novos significados.

Boas leituras! 